\title{
MUJERES DE HOY. . LÍDERES DE MAÑANA PERSPECTIVA DESDE LA EXPERIENCIA PROFESIONAL DE LA INGENIERÍA
}

Carmen Flores $\left(^{*}\right)$

Palabras clave: Mujer; Trabajo; Liderazgo

\section{Desarrollo:}

En la actualidad, la mujer ha dejado de ser esa persona que sólo se movía en el ámbito hogareño, para pasar a ser un ejemplo de trabajo y tesón ante la absorta mirada masculina.
En los tiempos que corren el círculo vicioso entre la ambición y el poder llevan a la mujer a superarse día tras día atravesando obstáculos y transgrediendo los límites impuestos por nuestra sociedad, ubicándola en puestos de trabajo que antes sólo eran vistos como una utopía.

La incorporación de la mujer al mundo del trabajo, especialmente en posiciones de

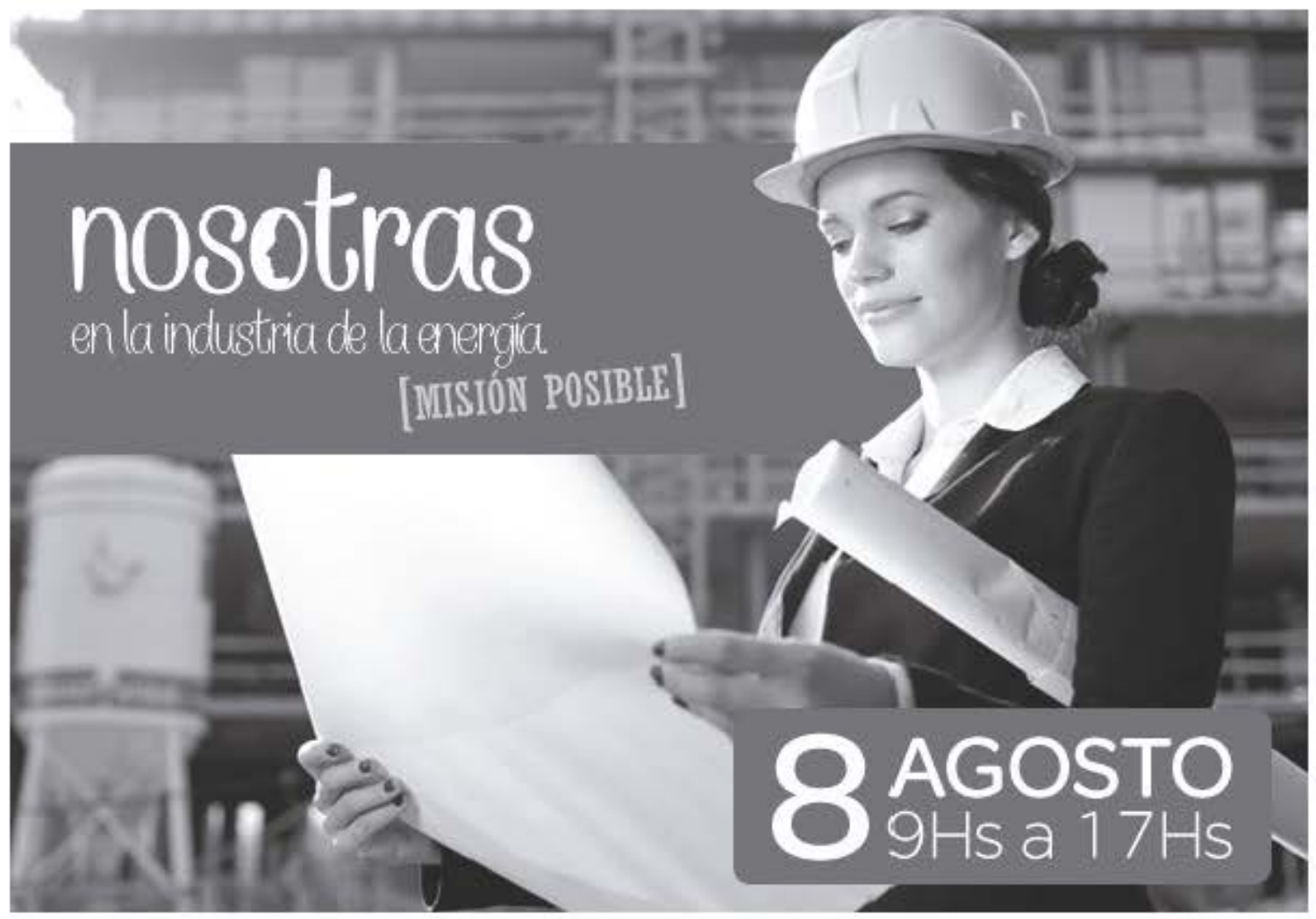

Figura 1: Encuentro de mujeres profesionales en la industria de la Energía

(*) Departamento Ingeniería - Facultad de Ciencias Exactas y Naturales y Agrimensura - UNNE. carmenflores2@hotmail.com.ar 
decisión es un hecho bastante reciente en el mundo laboral.

Las mujeres que se desempeñan en la industria de la gestión de la energía eléctrica enfrentan los desafíos propios del género y además los específicos de un mercado históricamente gerenciado por hombres.

Por tal motivo Schneider Electric Argentina quiso agasajar a la mujer que ocupa un lugar en el ámbito energético, y realizó una capacitación el 8 de agosto próximo pasado del corriente año en el Buenos Aires Grand Hotel de Recoleta; a cargo de Agostina Fasanella de Consultora Liderarte.

Con el objeto de obtener un aprendizaje distinto y en sintonía con las necesidades de la mujer ya sean tanto dentro como fuera de la empresa, y así poder expresar contenidos de nuestro interés y una metodología creativa para poder enriquecernos y compartir experiencias.
Profesionales del sector eléctrico vimos como una muestra de sensibilidad por parte de esta empresa al compartir con nosotras una experiencia poco usual, superando los límites comerciales para pasar a ser una relación más personal que ayude a enfrentar la vorágine de lo cotidiano entre la casa y el trabajo.

Asistimos a tal evento, mujeres de todo el país, que de una u otra forma tenemos relación con el sector energético, como ser la Ing. Samira Dilchoff y la Ing. Viviana Chomiczak, de Secheep (Presidencia Roque Saenz Peña) Chaco; Estela Carabajal (Ejecutiva de cuentas de la revista Petroquímica) Buenos Aires; Ing. María Rosa Guajardo (de la transportista Distrocuyo) Mendoza; Ing. Norma Díaz, Ing. Ana María Ugartemendia y Analía Filippini (DPEC), Ing. Daniela Villalba (Secretaría de Energía), como así también profesionales y no, de La Pampa; Neuquén; Córdoba, entre otras.

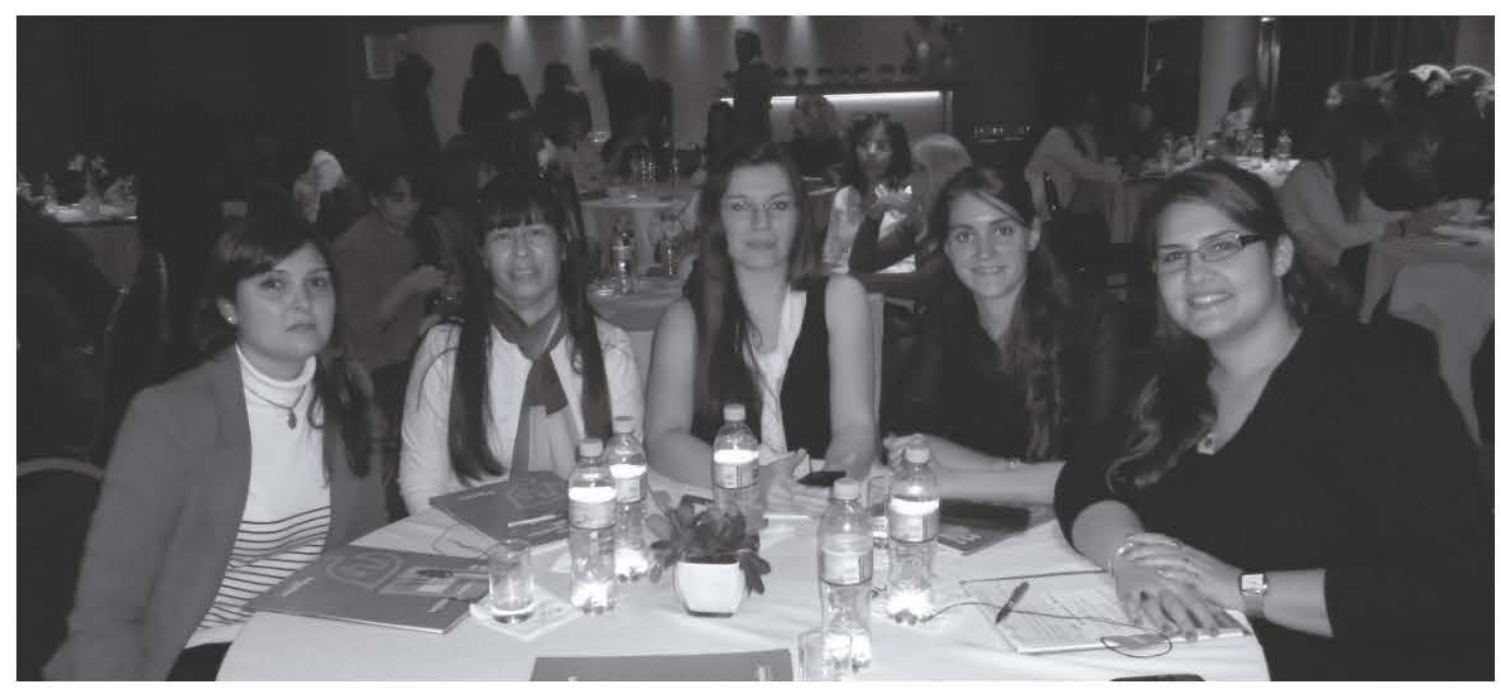

Figura 2: Intercambio de Experiencias de Ingenieras en Argentina

Centrando como ejemplo la destacada presencia de la Presidente de Schneider Electric Sudamérica, la brasileña Ingeniera Eléctrica Tania Cosentino, quien no sólo nos sorprendió con su participación sino que nos incitó a aceptar desafíos y correr los riesgos que constantemente se presentan en nuestra profesión. 
Con mucha seguridad la Ingeniera durante su charla dijo: - "La visión de una mujer es distinta a la del hombre, por eso queremos tener más mujeres en nuestra empresa, para mantener la diversidad, ya que esas diferencias son capaces de proporcionar un ambiente creativo e innovador."

Por otra parte aclaró: - "Históricamente el liderazgo del hombre es más guiado y más bien un estereotipo para que las cosas funcionen, en cambio la mujer se cree que tenemos una percepción emocional más fuerte, que somos capaces de llevar un ambiente de empatía más grande que el hombre, y por eso nosotras necesitamos aprender a ser más directivas, entonces el cambio está en aprender del pragmatismo masculino."

Con respecto a su visión y percepción a nivel global, como mujer de empresa, enfatizó:

- "Las mujeres vemos un mundo muy complicado donde la información fluye de diferentes fuentes a todo momento, que es imposible de mantener actualizado o totalmente alineado con lo que pasa. Hay una falta de talento en el mercado, necesitamos buscar mejores personas para que nuestra empresa pueda crecer, y la mujer a nuestro criterio es un talento que está escondido, porque se sabe que en Estados Unidos el $80 \%$ de las compras son decididas por mujeres y en Latinoamérica sólo el $67 \%$ son las que deciden. Entonces hay que escucharlas, bay que saber lo que piensan, lo que quieren y tenerlas como aliadas, ya que la dinámica de las cosas, donde todo debe pasar en tiempo real, nos obliga a desarrollar competencias que no necesitábamos en el pasado y eso también nos fuerza a tener un ambiente más diverso."

Por último expresó: - "Para mi la fórmula secreta es trabajar mucho, hay que entregar resultados y para la mujer especificamente, hay que buscar el crecimiento, si queremos y tene- mos la ambición de crecer, porque asi lo hace el hombre. . y muy bien. Él si quiere una posición lucha por ella, aunque no esté preparado, en cambio la mujer quiere estar un $150 \%$ lista y solamente después va a aplicar una posición, pienso que podríamos hacerlo diferente; yo lo bice, entonces cuando quise ser la Presidente brasileña en la unidad de Schneider Brasil, antes de ser la Presidente de Sudamérica, me apunté como candidata en todo el proceso y me esforcé por lograrlo. Por eso para llegar adelante hay que ayudar a otras mujeres y poner pasión en lo que uno hace."

Como broche de oro, las organizadoras del evento: Ing. Daniela Quiroga (Gerente de Ventas) y la Arquitecta Silvia Butera (Especialista en Comunicaciones de Marketing de Infraestructuras y Edificios) de Schneider Electric, nos expresaron su agradecimiento por nuestra participación en un evento tan especial y querido por nosotras, que más allá de haber sido un evento corporativo, nos ha movilizado la emoción al recibir una inmensa gratificación por todo lo que nos han dado desde el momento que empezamos a convocarlas y que nos quedará en el recuerdo por siempre.

Como experiencia personal debo decir que es muy gratificante esforzarse en hacer y aplicar la profesión que uno ama. Que no es obstáculo la diferencia de género, con toda la carga que ello implica, que existe "Nuestro Tiempo", como mujer y como profesional; que día a día se valora más el sacrificio y el apoyo de quienes nos rodean: familia, colegas, jefes. Que no es imposible "llegar" a las metas, que el hombre, en nuestra profesión tiene la mente abierta hacia el futuro, al cambio, a nuevas experiencias donde la mujer ya no es una simple observadora, sino partícipe en la toma de decisiones y aplicar su criterio a todo aquello que sea en pos de un beneficio para su empresa. 